\title{
nuvA, an Aspergillus nidulans gene involved in DNA repair and recombination, is a homologue of Saccharomyces cerevisiae RAD18 and Neurospora crassa uvs-2
}

\author{
Lesley Iwanejko, † Catherine Cotton, $\ddagger$ Gary Jones, § Brian Tomsett and \\ Peter Strike
}

Department of Genetics and Microbiology, The University of Liverpool, Donnan Laboratories, Liverpool L69 3BX, UK
Author for correspondence: Peter Strike. Tel: +44 151794 3620. Fax : +44 1517943655.
e-mail: strike@liv.ac.uk
A $40 \mathrm{~kb}$ genomic clone and $2.3 \mathrm{~kb}$ EcoRI subclone that rescued the DNA repair and recombination defects of the Aspergillus nidulans nuvA11 mutant were isolated and the subclone sequenced. The subclone hybridized to a cosmid in a chromosome-specific library confirming the assignment of nuvA to linkage group IV and indicating its closeness to bimD. Amplification by PCR clarified the relative positions of nuvA and bimD. A region identified within the subclone, encoding a C3HC4 zinc finger motif, was used as a probe to retrieve a CDNA clone. Sequencing of this clone showed that the nuvA gene has an ORF of $1329 \mathrm{bp}$ with two introns of $51 \mathrm{bp}$ and $60 \mathrm{bp}$. Expression of nuvA appears to be extremely low. The putative NUVA polypeptide has two zinc finger motifs, a molecular mass of $48906 \mathrm{Da}$ and has $39 \%$ identity with the Neurospora crassa uvs-2 and $25 \%$ identity with the Saccharomyces cerevisiae RAD18 translation products. Although mutations in nuvA, uvs-2 and RAD18 produce similar phenotypes, only the nuvA11 mutation affects meiotic recombination. A role for nuvA in both DNA repair and genetic recombination is proposed.

Keywords: Aspergillus nidulans, DNA repair, recombination, $\mathrm{C} 3 \mathrm{HC} 4$ zinc finger motif, nuv $A, \mathrm{RAD} 18$

\section{INTRODUCTION}

The processes of DNA repair and recombination play a pivotal role in the proper segregation of chromosomes at meiosis as well as the maintenance of genome integrity and the generation of genetic diversity. To understand these processes in eukaryotes better, we have undertaken a study of Aspergillus nidulans as it is multicellular and biochemically and morphologically its mitotic cell-cycle

tPresent address: Department of Cancer Genetics, Paterson Institute for Cancer Research, Christie Hospital NHS Trust, Wilmslow Road, Manchester M20 9BX, UK.

¥Present address: Department of Biological and Chemical Science, Whitelands College, Roehampton Institute of Higher Education, Sutherland Grove, London SW15 35N, UK.

\$Present address: School of Biological Sciences, University of Wales Swansea, Singleton Park, Swansea SA2 8PP, UK.

Abbreviations: MNNG, $N$-methyl- $N$-nitro- $N$-nitrosoguanidine; 4NQO, 4-nitroquinolene-1-oxide; RT, reverse transcriptase.

The EMBL, Genbank and DDBJ accession numbers for the nucleotide sequences reported in this paper are $Z 49875$ (genomic DNA sequence) and Z49834 (CDNA sequence). resembles that of mammalian cells in that a substantial proportion of the vegetative cell-cycle is spent in G2 (Bainbridge, 1971; Bergen \& Morris, 1983). This is important with respect to studies of mitotic recombination since it is believed that gene conversion and crossing-over are different outcomes of the same process, with gene conversion taking place during the $\mathrm{G} 1$ phase of the mitotic cell-cycle, whilst the G2 phase is associated with cross-over events (Roman \& Ruzinski, 1990). Studies with Aspergillus therefore provide a valuable complement to the extensive studies in Saccharomyces cerevisiae which is single-celled and spends much of its time in G1.

In a previous paper (Osman $e t$ al., 1991) we reported the isolation of the $A$. nidulans nuv $A 11$ mutation, a recessive, single gene defect on linkage group IV, originally identified as causing sensitivity to the DNA damaging agents $N$-methyl- $N^{\prime}$-nitro- $N$-nitrosoguanidine (MNNG) and 4-nitroquinolene-1-oxide (4NQO). The nuv $A 11$ mutants were shown to have a complex phenotype. Haploids are slow growing and have a 'crinkly' mor- 
Table 1. Strains used in this study

\begin{tabular}{|c|c|c|}
\hline Strain & Genotype and relevant phenotype & Source or reference \\
\hline \multicolumn{3}{|l|}{ E. coli } \\
\hline DH1 & $\begin{array}{l}\mathrm{F}^{\prime} \operatorname{rec} A 1 \text { end } A 1 \text { gyr } A 96 \text { thi-1 bsd } \mathrm{R} 17\left(\mathrm{r}_{\mathrm{k}}^{-}, \mathrm{m}_{\mathrm{k}}^{-}\right) \sup E 44 \\
\quad \operatorname{rel} A 1 \mathrm{1}^{-}\end{array}$ & Hanahan (1983) \\
\hline XL1-blue & $\begin{array}{l}\operatorname{rec} A 1 \text { end } A 1 \text { gyr } A 96 \text { thi-1 bsdR } 17\left(\mathrm{r}_{\mathrm{k}}^{-}, \mathrm{m}_{\mathrm{k}}^{+}\right) \text {supE E44 } \\
\quad \operatorname{rel} A 1 \text { lac }\left[\mathrm{F}^{\prime} \text { pro } A B \text { lac }{ }^{\mathrm{a}} \mathrm{Z} \Delta \mathrm{M} 15 \text { Tn } 10\left(\text { tet }^{\mathrm{r}}\right)\right]\end{array}$ & Bullock et al. (1987) \\
\hline SOLR $^{\mathrm{TM}}$ & $\begin{array}{l}\text { sbcC recB recJ uvrC umuC:: } \operatorname{Tn} 5\left(\mathrm{kan}^{\mathrm{r}}\right) \\
\text { e14-(mor } A), \Delta\left(m c r C B-b s d S M R-m r^{\mathrm{r}}\right) 171\left[\mathrm{~F}^{\prime} \text { pro } A B \text { lac } I^{\mathrm{q}}\right. \\
\mathrm{Z} \Delta \mathrm{M} 15] \text { end } A 1 \text { gyr } A 96 \text { thi-1 lac rel } A 1 \lambda^{\mathrm{r}}, \mathrm{Su}^{-} \text {(non- } \\
\text { suppressing) }\end{array}$ & Stratagene \\
\hline \multicolumn{3}{|c|}{ F1 helper phage } \\
\hline ExAssist $^{\mathrm{TM}}$ & $\begin{array}{l}\text { Interference-resistant helper phage containing amber } \\
\text { mutations in genes I and II ( } 5 \mathrm{~kb} \text {, single-stranded) }\end{array}$ & Stratagene \\
\hline \multicolumn{3}{|c|}{ A. nidulans nuv $A^{+}$strains } \\
\hline $\mathrm{L} 20$ & $w A 3$ paba $A 1$ & Liverpool stock \\
\hline A517 & $\begin{array}{l}\text { ribo } A 1 \text { y } A 2 \text { adE20; metbG1 suC11adE20 palC4 } \\
\text { pabaB22 pyro } A 4 \text { (a meiotic mapping strain for linkage } \\
\text { group IV) }\end{array}$ & $\begin{array}{l}\text { Fungal Genetics Stock } \\
\text { Center (FGSC) }\end{array}$ \\
\hline B 608 & puA1 wA3; niiAniaD 608 & Tomsett \& Cove (1979) \\
\hline CS387 & $\begin{array}{l}\text { y } A 2 \text { lu } A 1 \text {; niaD } 26 \\
\text { (A pair of strains carrying non-overlapping deletions in } \\
\text { the niaD gene allowing selection for nitrate, utilizing } \\
\text { products of intragenic recombination) }\end{array}$ & Tomsett \& Cove (1979) \\
\hline L600 & $\begin{array}{l}\text { pyrG89 y A2; niaD26 (previously referred to as } \\
\text { TYS3870) }\end{array}$ & Osman et al. (1991) \\
\hline L604 & pyrG89 y $A 2$ lu $A 1 ;$ niaD26 & This study \\
\hline \multicolumn{3}{|c|}{ A. nidulans nuvA11 strains } \\
\hline L601 & $\begin{array}{l}\text { pyrG89 y } A 2 ; \text { nuv } A 11 ; \text { niaD26 (previously referred to } \\
\text { as TYS3871) }\end{array}$ & Osman et al. (1991) \\
\hline L602 & $\begin{array}{l}p u A 1 w A 3 ; \text { nuv } A 11 ; \text { nii } A \text { niaD } 6608 \text { (previously referred } \\
\text { to as } \mathrm{B} 608 \text { nw } 11)\end{array}$ & Osman et al. (1991) \\
\hline L603 & $\begin{array}{l}\text { y A2 luA1; nuv } A 11 ; \text { niaD26 (previously referred to as } \\
\text { CS387nuv11) } \\
\text { (A pair of nuv } A 11 \text { strains carrying non-overlapping } \\
\text { deletions in the niaD gene allowing selection for } \\
\text { nitrate, utilizing products of intragenic recombination) }\end{array}$ & Osman et al. (1991) \\
\hline $\mathrm{L} 605$ & pyrG89 y $A 2$ lu $A 1 ;$ nuv $A 11 ;$ niaD26 & This study \\
\hline
\end{tabular}

phology, whereas nuv $A 11$ homozygous diploids have a normal growth rate but are very unstable. Mitotic recombination frequencies are significantly elevated in these diploids, yet meiotic recombination is virtually absent in sexual crosses between two nuv $A 11$ strains, even though the fertility and ascospore viability of such crosses appears to be unaffected. The nuv $A 11$ mutation also results in sensitivity to $\mathrm{UV}$ and $\gamma$ irradiation and higher UV-induced mutation frequencies, but not $\gamma$-ray-induced mutation frequencies (S. May, this laboratory, unpublished observations). The nuv $A 11$ mutant phenotype was previously compared (Osman et al., 1991) with those of the $S$. cerevisiae RAD52 epistasis group mutants rad50 and rad52 which are defective in their repair of double-strand breaks (Game, 1983; Haynes \& Kunz, 1981). Although similar, none of the phenotypes were identical to that caused by the nuv $A 11$ allele. We therefore aimed to clone the nuv $A$ gene to understand more fully the role the gene product plays in DNA repair and recombination.

In this paper we describe the cloning of the nuv $A$ gene by complementation of the nuv $A 11$ phenotype. We also describe the isolation of the nuv $A$ cDNA sequence. The presumed location of the nuv $A$ gene, close to $\operatorname{bim} D$ and uws H, on chromosome IV (Käfer \& Chae, 1994) is also presented. The nucleotide and putative amino acid sequences are discussed and compared with the known DNA repair proteins UVS-2 of Neurospora crassa (Tomita et al., 1993) and RAD18 of S. cerevisiae (Jones et al., 1988).

\section{METHODS}

Strains, vectors and libraries. Bacterial and fungal strains used in this study are described in Table 1 . Both the cosmid library, containing $30-40 \mathrm{~kb}$ wild-type $A$. nidulans genomic DNA inserts 
Table 2. Vectors and constructs used in this study

\begin{tabular}{|c|c|c|c|}
\hline Vector & $\begin{array}{l}\text { Selectable } \\
\text { marker* }\end{array}$ & Features & Source or reference \\
\hline \multicolumn{4}{|l|}{ E. coli } \\
\hline pBluescript SK- & $A p^{r}$ & $2.96 \mathrm{~kb}$ phagemid & Stratagene \\
\hline pGEM-T System I & $A p^{r}$ & $\begin{array}{l}\text { Supplied as an EcoRV-cleaved pGEM- } 5 \mathrm{Zf}(+) \text { vector } \\
\text { treated with terminal transferase to produce } 3^{\prime} \\
\text { overhangs for direct PCR cloning }\end{array}$ & Promega \\
\hline$\lambda \mathrm{ZAP}$ & $A p^{r}$ & $\begin{array}{l}\lambda \text { insertional vector. In vivo excision releases cloned } \\
\text { DNA in pBluescript SK }-\end{array}$ & Stratagene \\
\hline pWE15 & $A p^{r}$ & $\begin{array}{l}8.8 \mathrm{~kb} \text { cosmid. Also carries the neomycin marker } \\
\text { under the control of the SV } 40 \text { promoter for use in } \\
\text { eukaryotes }\end{array}$ & Stratagene \\
\hline \multicolumn{4}{|l|}{ E. coli/A. nidulans } \\
\hline pCAP2 & $\mathrm{pyr} 4 / A p^{r}$ & $\begin{array}{l}\text { Cosmid containing the ans } 1 \text { transformation- } \\
\text { enhancing sequence of } A \text {. nidulans and a unique } \\
\text { Bam HI cloning site }\end{array}$ & $\begin{array}{l}\text { Ballance \& Turner } \\
\text { (1985) }\end{array}$ \\
\hline pRG4 & $\mathrm{pyr} 4 / A p^{r}$ & $\begin{array}{l}\text { pUC19-based vector derived from pRG3. Contains } \\
\text { the pBluescript SK - polylinker }\end{array}$ & $\begin{array}{l}\text { Waring et al. } \\
\text { (1989) }\end{array}$ \\
\hline \multicolumn{4}{|l|}{ Constructs } \\
\hline pSF20 & pyr4/Ap ${ }^{r}$ & pRG3 containing a $\gamma$-actin gene fragment & Fidel et al. (1988) \\
\hline pNUV11A40 & $\mathrm{pyr} 4 / \mathrm{Ap}^{\mathrm{r}}$ & $\begin{array}{l}\text { pCAP2 containing a } 40 \mathrm{~kb} A \text {. nidulans genomic } \\
\text { DNA insert }\end{array}$ & Osman et al. (1991) \\
\hline pEA14 & pyr4/Ap ${ }^{r}$ & $\begin{array}{l}\mathrm{pRG} 4 \text { containing a } 2.5 \mathrm{~kb} A \text {. nidulans genomic DNA } \\
\text { insert }\end{array}$ & This study \\
\hline pLW100 & $A p^{r}$ & pBluescript $\mathrm{SK}-$ containing the nuv $A \mathrm{cDNA}$ insert & This study \\
\hline pLW101 & $A p^{r}$ & pGEM-T containing the $5^{\prime}$ end of the nuv $A$ gene & This study \\
\hline pW17F02 & $A p^{r}$ & $\begin{array}{l}\text { pWE15 clone of } A . \text { nidulans genomic DNA that } \\
\text { hybridized the pEA14 insert }\end{array}$ & $\begin{array}{l}\text { This study } \\
\text { This study }\end{array}$ \\
\hline
\end{tabular}

*Ap, ampicillin.

in pWE15 (Brody et al., 1991), and the $A$. nidulans $24 \mathrm{~h}$ developmental cDNA library in $\lambda \mathrm{ZAP}$ (Aramayo \& Timberlake, 1990) were obtained from the Fungal Genetics Stock Centre (FGSC), Kansas City, Kansas 66160-7420, USA. Vectors and libraries (Table 2) were propagated in E. coli XL1blue using standard techniques and media (Sambrook et al., 1989). A. nidulans strains were grown in standard media (Cove, 1966) except mutagen-containing medium which was made up to $\mathrm{pH}$ 6.0. Mutagens were added to cooled molten agar or liquid media. MNNG was freshly made in ethanol but 4NQO was kept at $-20^{\circ} \mathrm{C}$ as a stock solution $\left(1 \mathrm{mg} \mathrm{ml}^{-1}\right)$, also in ethanol. Standard genetic manipulations were employed throughout this study (Pontecorvo, 1953).

Assaying MNNG and 4NQO sensitivities. Mutagen sensitivities were assessed using the radial growth rates of point-inoculated colonies on agar plates containing various concentrations of MNNG (0.5-2.5 $\left.\mu \mathrm{g} \mathrm{ml}^{-1}\right)$ and 4NQO $\left(0.25-1.5 \mu \mathrm{g} \mathrm{ml}^{-1}\right)$. Plates were incubated at $37^{\circ} \mathrm{C}$ for $48 \mathrm{~h}$ prior to measuring.

Recombination assays. The $p u A 1$ and $w A 3$ markers on chromosome II and the $y A 2$ and $l u A 1$ markers on chromosome I were used to assess both mitotic and meiotic intergenic recombination frequencies (Osman et al., 1991). Pairs of strains carrying heteroallelic deletions in the niaD gene were used to assay mitotic and meiotic intragenic recombination frequencies as described previously (Osman et al., 1991).

Diploid stability and colony morphology. These were determined by visual assessment of diploid colonies on minimal base (MB) plates containing the appropriate supplements and nitrogen source. Test diploids were compared with homozygous wild-type diploids which are stable and morphologically homogeneous, and nuv $A 11$ homozygous diploids which are extremely unstable and morphologically diverse.

Fine mapping. Attempts were made to map the nuv $A 11$ mutation meiotically within linkage group IV using the meiotic mapping strain A517, employing standard genetic mapping techniques. A more accurate map position was obtained by hybridizing the cloned nuv $A$ gene to the pWE15 cosmid library and identifying the physical map location of the positively hybridizing clones (R. Prade, University of Georgia, personal communication).

DNA manipulations. Standard cloning techniques were used as described by Sambrook et al. (1989). Plasmids were prepared using an alkaline lysis method and Qiagen columns supplied by the manufacturer or by $\mathrm{CsCl}$ gradient purification (Sambrook $e t$ al., 1989). Double-stranded plasmid DNAs were sequenced using the dideoxynucleotide chain termination procedure (Sanger et al., 1977) with T7 DNA polymerase, according to the manufacturer's instructions (Pharmacia). PCR fragments were sequenced, after purification on an appropriate spin column (Pharmacia), on an Applied Biosystems 373A DNA Sequencer using the Taq DyeDeoxy Terminator Kit and protocol. Oligonucleotide sequencing and PCR primers were supplied by Pharmacia or synthesized on an Applied Biosystems 392 DNA/RNA synthesizer. Except where otherwise indicated, 


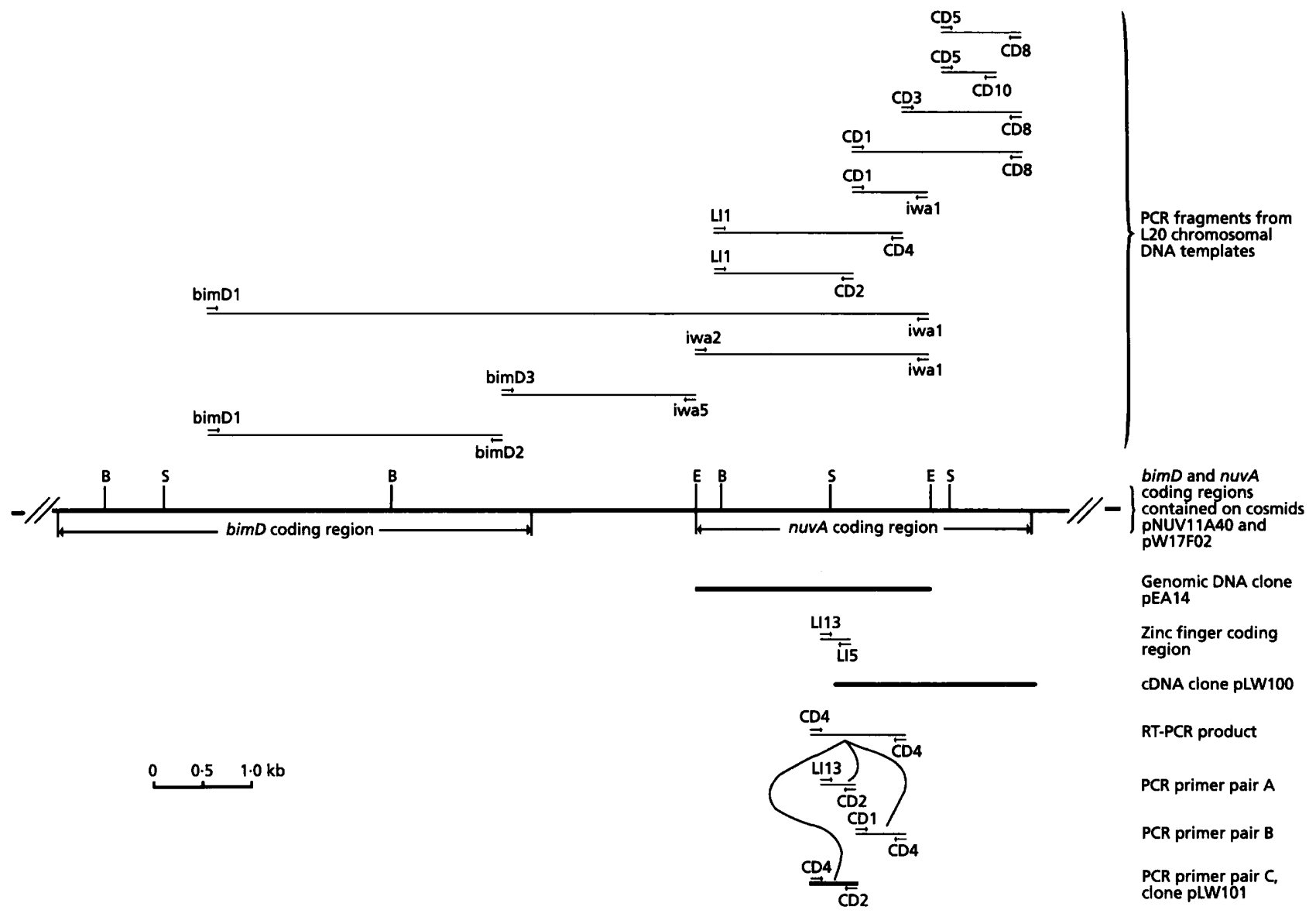

Fig. 1. Diagram of the $9.5 \mathrm{~kb}$ bimD/nuvA region of chromosome IV. All the BamHI (B) and Sstl (S) sites specific to this region and found on the cosmid clones pNUV11A40 and pW17F02 are marked, as are the EcoRI (E) sites used to subclone the $2.3 \mathrm{~kb}$ nuvA11-complementing fragment of PEA14. The location of the PCR primer pairs in this region and the size of their PCR products used to verify the contiguity of the various nuvA sequences and the orientation of the nuvA and bimD genes are shown above the restriction map. The sections covered by the nuvA genomic clone pEA14, the 'zinc finger' encoding region used as a probe, the $5^{\prime}$ truncated CDNA clone pLW100, and the RT-PCR product along with its subproducts are shown below the map.

PCR amplifications were performed on a Perkin Elmer DNA Thermal Cycler 480 using Gibco Taq DNA polymerase with the buffer and $\mathrm{MgCl}_{2}$ solutions supplied by the manufacturer. The oligonucleotide sequences of the PCR primers used in this study, most of which were originally designed for sequencing, are given below. ${ }^{32} \mathrm{P}$-labelled DNA probes were prepared essentially as described previously (Feinberg \& Vogelstein, 1983) using a random-primed DNA labelling kit (Boehringer Mannheim). Chromosomal DNA from $A$. nidulans was prepared by the Raeder \& Broda (1985) method. Plaque and colony hybridizations and Southern transfers were on to Gene Screen Plus nylon-based membranes (DuPont) using the manufacturer's recommended protocols. Hybridizations were carried out in a Techne hybridization oven using Blotto hybridization solution (Sambrook et al., 1989).

PCR Primers. The sequences of the DNA primers used were as follows. M13-20, GTAAAACGACGGCCAGT; M13-reverse, GGAAACAGCTATGACCATG; bimD1, CATCTATCGTCGATGCTGCGGG; bimD2, CTGGAACCGGGGATGCAGG; bimD3,CCTGCATCCCCGGTTCCAG;iwa1,GAATTCGCTTGGGAAGCTTGG; iwa2, GAATTCTGGCGTTGCAGAGG; iwa5, CCCAAGCCTCTGCAACGCCAG; LI1, GAGCGTACCATGACATTC; LI5, GACCATCTGTGCC-
GAC; LI13, AACGTCCCTCCGCTGCCA ; CD1, CCCTGTTCAGGTCATAG; CD2, CTATGACCTGAACAGGAG; CD3, GTGGAACGCCAATTGTG; CD4, CACAATTGGCGTTCCAC; CD5, GCTATCGACAATAGAACAG; CD8, CAAGAGCCGCTCTTGGTG; CD10, CAAAGTGGACGAGATCGG.

RNA manipulations. $A$. nidulans mRNA was purified from freshly grown and frozen mycelia using Dynabeads oligo(dT) $)_{25-30}$ (Dynal) according to the manufacturer's instructions. Northern blots were performed as described by Sambrook et al. (1989), but using 0.22 $\mathrm{M}$ formaldehyde in both the buffer and the agarose gel (Sylvers \& Beresten, 1993). RNA size markers were used according to manufacturer's instructions (Gibco). Reverse transcriptase (RT) reactions were performed with Tth DNA polymerase according to the manufacturer's protocol (Boehringer Mannheim). Additions of PCR buffer and EGTA prior to subsequent PCR of the RT product were also done according to manufacturer's recommendations, except that RNase $\mathrm{H}(2.7 \mathrm{U})$ (Gibco) was included in the PCR mix and the samples were incubated at $37{ }^{\circ} \mathrm{C}$ for $5 \mathrm{~min}$ prior to the $95^{\circ} \mathrm{C}$ denaturing step.

Modified 'RACE no more' RT PCR. This approach to finding the $5^{\prime}$-end of a transcript was first described by Weis (1994). In this 
modified version both the first strand synthesis and the subsequent PCR was carried out using the single nuv $A$-specific primer, CD4, shown in Fig. 1. Unlike the Weis version, in this protocol a single enzyme, $T$ th DNA polymerase (Boehringer Mannheim), was used to perform both the RT part of the procedure $\left(65^{\circ} \mathrm{C}\right.$ for $\left.20 \mathrm{~min}\right)$ and the subsequent PCR reaction (denature for $2 \mathrm{~min}$ at $95^{\circ} \mathrm{C}$ followed by 35 cycles of $95^{\circ} \mathrm{C}$ for $60 \mathrm{~s}, 55^{\circ} \mathrm{C}$ for $60 \mathrm{~s}, 72^{\circ} \mathrm{C}$ for $60 \mathrm{~s}$, finishing with $72^{\circ} \mathrm{C}$ for $5 \mathrm{~min}$ ) following the RNase $\mathrm{H}$ treatment $\left(37^{\circ} \mathrm{C}\right.$ for $5 \mathrm{~min}$ ). These modifications enabled the $\mathrm{R} T$ reaction to be carried out at a higher temperature, thereby reducing any secondary structure problems in the RNA templates and removing the requirement for a phenol/chloroform extraction and ethanol precipitation to change buffers for the PCR reaction.

Transformations. $A$. nidulans transformations were as described by Ballance \& Turner (1985). DNA samples for transformations were prepared following standard alkaline lysis mini-preparation procedures (Sambrook et al., 1989), then cleaned with Strataclean resin (Stratagene) according to manufacturer's instructions. E. coli was transformed using the heat-shockinduced method described by Sambrook et al. (1989) or by electroporation-induced transformation, according to the method recommended by the manufacturers of the electroporation apparatus (Bio-Rad).

DNA sequence analyses. DNA sequences and predicted amino acid sequences were analysed using programs contained within the Genetics Computer Group, Wisconsin Package, Version 8.0 (1994). In particular, programs TFASTA and FASTA, which compare the query sequence with those contained in the GenBank/EMBL database, were used to identify homologies to other genes and proteins. The GAP program (selecting the default parameters) was utilized in the alignment of the NUVA, RAD18 and UVS2 putative amino acid sequences.

\section{RESULTS AND DISCUSSION}

\section{Rescue of the nuvA11 phenotype by the genomic clone, pNUV11A40}

A $40 \mathrm{~kb} A$. nidulans genomic DNA clone, pNUV11A40 (Fig. 1), that restored the MNNG and 4NQO sensitivities of the nuvA11 mutant strain, L601, was described previously (Osman et al., 1991). The resistance of strain L601 transformed with pNUV11A40 was shown to be the same as that of an equivalent wild-type strain, L600, transformed with just the vector, pCAP2, whilst L601 remained hypersensitive to both agents when transformed with vector alone. There were several possible explanations for the observed increase in resistance of the pNUV11A40 transformants, including over-expression of an unrelated DNA repair gene due to duplication. Suppression of the MNNG and 4NQO sensitivities was not therefore considered conclusive evidence that pNUV11A40 carried the nuv $A$ gene. Confirmation that the clone was directly restoring the mutant allele was obtained by determining its effects on other aspects of the nuv $A 11$ phenotype. To determine its effects on recombination, pNUV11A 40 was used to transform the nuv $A 11$ mutant strain L605 which contains the $y A 2$ and $l u A 1$ markers on chromosome I and can be used for assessing intergenic recombination frequencies. It also carries the niaD26 deletion on chromosome VIII, one of the two niaD alleles used in intragenic recombination assays (Osman et al., 1991). Control transformants with the vector alone in L605 and also in the isogenic wild-type strain, L604, were created. The MNNG and 4NQO sensitivities of these haploid transformants were tested and found to be the same as the original transformants (Osman et al., 1991) (data not shown). Sexual crosses were carried out and diploids made with the new transformants and the nuv $A 11$ strain, L603, which contains the linkage group II markers $w A 3$ and $p u A 1$ plus the niaD allele, niiAniaD $\Delta 608$, the other deletion required for the intragenic recombination assays (Osman et al., 1991). The mitotic and meiotic, intergenic and intragenic, recombination frequencies were then determined as described previously (Osman et al., 1991). Mitotic intragenic (Table 3 ) and intergenic (Table 4) recombination frequencies in nuv $A 11 /$ nuv $A 11$ homozygous diploids made with the pNUV11A40 transformants were reduced to levels comparable to wild type as observed in PCAP2-transformed

Table 3. Mitotic and meiotic intragenic recombination frequencies in parental and transformed strains obtained using diploids and sexual crosses, respectively

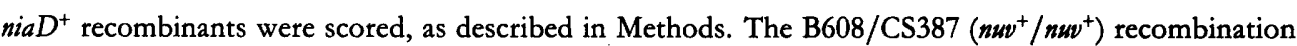
frequencies $\left(46.69 \times 10^{-3}\right.$ for mitotic and $1.07 \times 10^{-3}$ for meiotic) were taken as $100 \%$.

\begin{tabular}{|c|c|c|c|}
\hline Strains & Genotype & $\begin{array}{c}\text { Mitotic } \\
\text { recombination } \\
\text { frequency (\%) }\end{array}$ & $\begin{array}{c}\text { Meiotic } \\
\text { recombination } \\
\text { frequency }(\%)\end{array}$ \\
\hline B608/CS387 & $n u v A^{+} / n u v A^{+}$ & 100 & 100 \\
\hline $\mathrm{B} 608 / \mathrm{L} 603$ & $\operatorname{nuv} A^{+} / \operatorname{nuv} A^{-}$ & 112 & 136 \\
\hline B608/L605:pCAP & $n u v A^{+} / n w v A^{-}:: \mathrm{pCAP}$ & 119 & 112 \\
\hline B608/L605:pNUV11A40 & $n u v A^{+} / n u v A^{-}:: \mathrm{p} n u v A^{+}$ & 96 & 80 \\
\hline B608/L605:pEA14 & $n u v A^{+} / n u v A^{-}:: \mathrm{p} n u v A^{+}$ & 120 & 56 \\
\hline L602/L603 & $n u v A^{-} / n w v A^{-}$ & 870 & 5 \\
\hline L602/L605:pCAP2 & $n u v A^{-} / n u v A^{-}:: \mathrm{pCAP}$ & 660 & 5 \\
\hline L602/L605:pNUV11A40 & nuv $A^{-} /$nuv $A^{-}:: \operatorname{pnuv} A^{+}$ & 95 & 72 \\
\hline L602/L605:pEA14 & $n u v A^{-} / n u v A^{-}:: \mathrm{p} n u v A^{+}$ & 92 & 88 \\
\hline
\end{tabular}




\section{Table 4.Mitotic and meiotic intergenic recombination frequencies}

Mitotic intergenic recombination was measured by marker segregation in benlate-induced haploids arising from diploids constructed using the transformants, compared with wild-type and nw $A 11$ homozygous and heterozygous diploids. The values indicate the numbers of separate haploid colonies arising. Meiotic intergenic recombination frequencies were measured in map intervals between $y A 2$ and $l u A 1$ (68 cM apart on chromosome I) and also between $w A 3$ and $p u A 1$ ( $>200 \mathrm{cM}$ apart on chromosome II) (Clutterbuck, 1994) in crosses constructed with transformants, compared with the control wild-type and nuv $A 11$ homozygous and heterozygous crosses.

\begin{tabular}{|c|c|c|c|c|c|c|c|}
\hline \multirow[t]{3}{*}{ Strain } & \multirow[t]{3}{*}{ Genotype } & \multicolumn{4}{|c|}{ Mitotic recombination } & \multirow{2}{*}{\multicolumn{2}{|c|}{$\begin{array}{c}\text { Meiotic recombination } \\
(\mathbf{c M})\end{array}$}} \\
\hline & & \multicolumn{2}{|c|}{ Linkage group I $y A 2-l u A 1$} & \multicolumn{2}{|c|}{ Linkage group II $w A 3-p u A 1$} & & \\
\hline & & Recombinant & Parental & Recombinant & Parental & $\begin{array}{c}\text { Linkage } \\
\text { group I } \\
y A 2-l u A 1\end{array}$ & $\begin{array}{c}\text { Linkage } \\
\text { group II } \\
w A 3-p u A I\end{array}$ \\
\hline $\mathrm{B} 608 / \mathrm{CS} 387$ & $n u v A^{+} / n u v A^{+}$ & 0 & 118 & 0 & 179 & $41 \cdot 20$ & $42 \cdot 50$ \\
\hline B608/L603 & nuv $A^{+} / \operatorname{nuv} A^{-}$ & 0 & 133 & 0 & 191 & $44 \cdot 40$ & $41 \cdot 60$ \\
\hline B608/L605:pCAP & $\begin{array}{l}n u v A^{+} / n w v A^{-} \\
:: \mathrm{pCAP}\end{array}$ & 2 & 152 & 1 & 117 & $37 \cdot 70$ & $52 \cdot 70$ \\
\hline B608/L605:pNUV11A40 & $\begin{array}{l}\text { nuv } A^{+} / \text {nuv } A^{-} \\
:: \operatorname{pnuv} A^{+}\end{array}$ & 0 & 123 & 0 & 141 & $41 \cdot 60$ & $43 \cdot 21$ \\
\hline B608/L605:pEA14 & $\begin{array}{l}n w v A^{+} / n w v A^{-} \\
:: \mathrm{p} n w w A^{+}\end{array}$ & 0 & 116 & 4 & 127 & $43 \cdot 80$ & $46 \cdot 85$ \\
\hline L602/L603 & nuv $A^{-} / n u v A^{-}$ & 122 & 43 & 101 & 123 & $29 \cdot 80$ & $47 \cdot 80$ \\
\hline L602/L605:pCAP2 & $\begin{array}{l}n u v A^{-} / n u v A^{-} \\
:: \mathrm{pCAP}\end{array}$ & 66 & 92 & 72 & 86 & $31 \cdot 86$ & $45 \cdot 40$ \\
\hline L602/L605:pNUV11A40 & $\begin{array}{l}n u v A^{-} / n w v A^{-} \\
:: \operatorname{p} n u v A^{+}\end{array}$ & 0 & 76 & 1 & 93 & $41 \cdot 20$ & $53 \cdot 40$ \\
\hline L602/L605:pEA14 & $\begin{array}{l}\operatorname{nuv} A^{-} / \operatorname{nuv} A^{-} \\
:: \mathrm{p} n w A^{+}\end{array}$ & 1 & 134 & 3 & 134 & $34 \cdot 10$ & $56 \cdot 50$ \\
\hline
\end{tabular}

nuv $A 11 /+$ heterozygous diploids. Recombination in nuv $A 11 /$ nuv $A 11$ homozygous diploids made with the pCAP2 transformants remained high. Similarly, both intergenic (Table 4) and intragenic (Table 3) meiotic recombination frequencies in nuv $A 11$ homozygous crosses with the pNUV11A40 transformants were restored to wild-type values. The morphological variation of nwv $A 11$ mutants and the instability of nuv $A 11 /$ nuv $A 11$ homozygous diploids were not fully restored to wild type by pNUV11A40 (data not shown), although both were much reduced. A satisfactory explanation for this anomaly has yet to be determined, although it may be due to the continued expression of the defective copy of the nuv $A 11$ gene. Southern blots of all transformants were consistent with a single homologous integration event, which would result in the presence of both a wild-type and mutated copy of the nuv $A$ gene (data not shown).

\section{pEA14, the smallest fragment able to restore nuvA11 to wild type}

EcoRI and $K p n I$ restriction enzyme digests of the $40 \mathrm{~kb}$ pNUV11A40 $A$. nidulans genomic DNA insert were performed and the resultant fragments ligated into the multiple cloning site of the Escherichia coli/ $A$. nidulans shuttle vector $\mathrm{pRG} 4$. These subclones were then used to transform the nuvA11 mutant strain L605. Several of the uridine and uracil prototrophic colonies from each of the transformations, including those transformed with the vector alone, were tested for sensitivity to MNNG and $4 \mathrm{NQO}$ (data not shown). Only one of the subclones, pEA14 (Fig. 1), which contained a $2 \cdot 3 \mathrm{~kb}$ EcoRI insert, consistently produced resistant transformants, Southern blots of which were consistent with a homologous integration of the plasmid into the nuv $A$ locus (data not shown). The ability of this subclone to rescue the nuv $A 11$ mitotic and meiotic (Tables 3 and 4) recombination defects was tested and found to be comparable to that of the larger clone, pNUV11 A40. pEA14, like pNUV11 A40, also failed to rescue fully the morphological defects and diploid instability associated with the nuv $A 11$ phenotype. From these observations it was deduced that the nuv $A$ gene was contained, at least in part, on the $2.3 \mathrm{~kb} E c o \mathrm{RI}$ fragment. This fragment was subjected to DNA sequencing and restriction enzyme analysis to determine the extent and nature of the nuv $A$ gene. The results of these analyses, when compared to the DNA sequence of a cDNA clone (described below), demonstrated that the pEA14 subclone contained only the $5^{\prime}$ end of the nuv $A$ coding region (Figs $1 \& 2$ ). A series of PCRs, using primers directed against both the genomic and cDNA clones, were performed with a chromosomal DNA template from the $A$. nidulans wild-type strain L20. The PCR fragments obtained (Fig. 1) were of the predicted sizes and were consistent with both the genomic and the cDNA clones being derived from contiguous sequences 
1 GAATTCTGGC GTTGCAGAGG CTTGGGTGGT TCCTCGTTCT TGATTTCAGC TTPTCCCGGT 61 TGTAAGGGTT CAGATTGGGC AGGTCTTTTT GCTGGCACCG TACTCGAAGG GGGAGGTGGT 121 GGTCGTACAC CTGTTCTCCT CTGTTCGACT TCAAGTCAGC AAGACAAGGC TTACATGATA 181 GTTTTCTACA TGTAGACGAG CGTACCATGA CATTCTGATT TGAACATCCC ACTGCTTCGT 241 ACTCCAGTGG ATCCTCGTGC GCATGGTTAA CCAGCATCTC ACGACTGACA TCAGTGAGCA OO1 CATTGAGATC CTGCAGTATG GTAGGTTGCA GGCTATAAAT GTATATAGAA GATATTGACT 361 CAAATGTGGA TTPTGCATCT GTAGCGCTAG TTAGTGACTA TTAGAGGCAT GGCCGCCCGT 481 AGGAACTTGG TCCGATTCAG TTTCCGGGTT GGGCAGCGAG CTGCTGA TAT AAGCACTGCT 541 AGGAACTTGG TCCGATTCAG TTTCCGGGTT GGGCAGCGAG CTGCTGATAT AAGCACTGCT 501 TGGCATTATA TCATCTTCGT TGTCACCGTT GCCATTGGCA GTGGCTCCGT TCTCACGGGT 661 GGAGTTTTCA TTGAGGTGAA ACTCATAGAG CATTCTGTCC ACATTTAATA TCATCTTAAA 721 TTTTATGATT TAATTGACTT ACTGCTTCGC GAGGGTGCTG TGTACTCTCA ATGCTCGGCC 781 CAGCGAGCGA TATGTAACCT ATTGTCAATG CAGGTTAAGA ATTGAGTCGC AATTTTCAGT 841 TACTGACCGT ACGACGTTCA TGAAAGACAG CTGTCCGCCA AAAACTTCTT ATGATCAGCG 901 ATAGCCATCC TTTCGACGAA TTTTGGCGCC GTTGTTGTAT ATCGGAGATG CAATGAGCAG 961 GCACTGTGAT CGACGCGTGA CGCCGAACCA CTTTACGCGT ATCAGTCAGC CAGTCTTGGC 1081 ATACCGAGAT ATAAGCAAGA GCTTCGCGAG AAGTCTACCT GGAAGTGCGG CTACCATCGC 1141 GTPTGTACTG ATG GAG CCG ACA TTT GAC ATC CCG GAC TCG ACC GAT TGG CTC

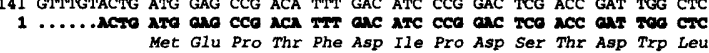

1193 GAC ACG CCG TTA ACG CTT CTC GCG CCT TTT GAA ACG TCC CTC CGC TGC CAG

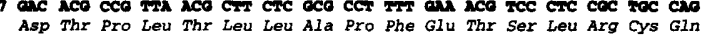

1244 GTC TGC AAG GAC TTT TTC GAC AAC CCT GTG ATC ACG TCG TGC AGC CAC ACA

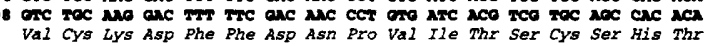

1295 TTT TGC TCG CTA TGT ATT CGC CGG TGT CTG AGT ACA GAG GGA AAA TGC CCT

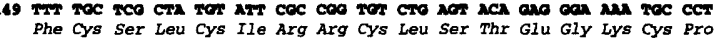

1346 ACA TGC CGG AGC TCT GAT CAG GAG CTG AAG TTG CGT CGC AAT TGG GTG GTG

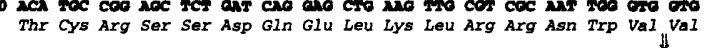

1397 CAG GAG CTG GTG GAG GGG TTT AAG AAT GCT CGA CCG AGC ATA TTA CAG CTA

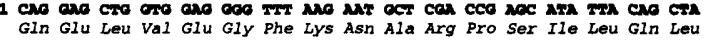

1448 GCT AGG ATG GCA CAA ACT GGC ACG GAT GAT AGT GGA GAT TTG GCT GCG GAA

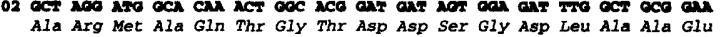

1499 GAG CCT GCA TCG AAA AAG CGG AAA ATA GAG CAG AAT GCC ATT GTC GGC ACA

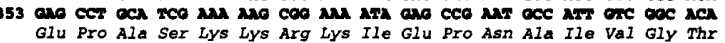
1550 GAT GGT CTT CCT GAG GAG GGT ATT CGC ACC CGA TCA CAG AGT CGA GGA GCT

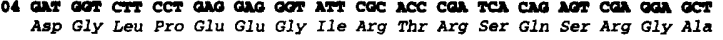

1601 AGT CGG CAG CCA CAA GCT ACT CCT GTT CAG GTC ATA GAT GAT GGT AAT GAT

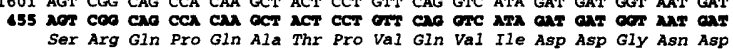

1651 GAG GAC TAT ATG CCG G GTAGGTTTTT CAACGCGTTC ATCCGTGGTA TCCACTAACT

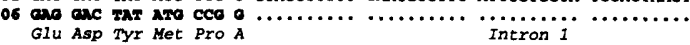

1707 TTGGTTTGCA G AC GGC TTG GTG CCG TGC CCT GTA TGT GGA CGG AGG ATG AAA

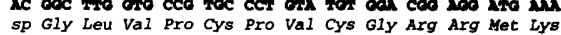

1759 GAA GAA GCC GTG TTC CGT CAT CTT GAC TCC TGT ACT GGG ACT GCA GAG GAA

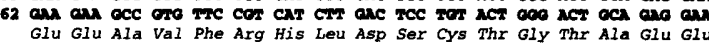
1810 CTG AAG CCA GCC GCT TT GGGTAAGATT CCATACCGCT AGTGGCAGGT TGCTATACAT

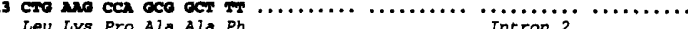

1867 agTGCTAATC CAGTGCCTA T GGG TCG TTA GCA CCT GGC CCG CGC AAA TCG TTC

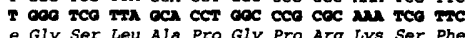
1930 CTA GCA GCC ACG GGA AAA CCA CCG GAA AGA CTT CCT GTT ATA AAT TAT TCT

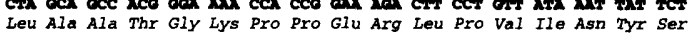

1981 CTA CTG AAA GAT ACG GTG CTA CGA AAG AAA TTG AAG GAT CTG GGC ATA CCA

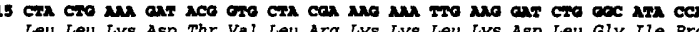

2032 AAC TGG GGC CCG CGA GCT TTG CTG CAA AGA CGA CAT ACT GAG TGG TTG AAC

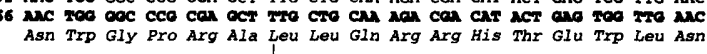
2083 TTG TGG AAC GCC AAT TGT GAC TCT AGG ACA CCG AAA CCG AAA CGA GAG TTA

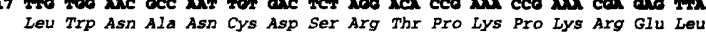

2134 CTG CGT GAA TTA GAC GTC TGG GAG CGG ACC CAA GGA GGA AAT TCA GTC ACT

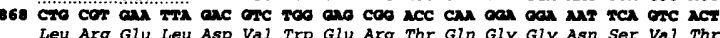

2185 CCC ACC GAC CCA ACG AAC GCT GTA ATG AAT AAG GAT TTT AAT ACG GAA GAG

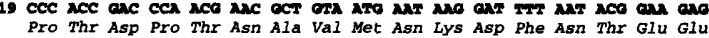

2236 TGG TCG GCG AAC TAT GAC ACA GAT TTC AAG GCA TTG ATC GCG AAT GCG CGA

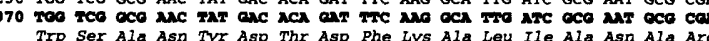
2287 AAG AAA AAC GAT GCT GTT ATT CGC TCA ACA ATA CCG AAC GCT TCC CAA GCO

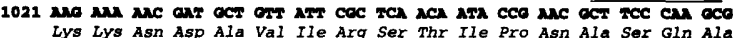
2338 AAT TCG GAT ACG CCG CGA AGC GCC CAA CTC GTT GAT CAG CCT ATC GAA GCT

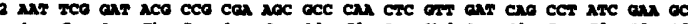
Asn Ser Asp thr Pro Arg Ser Ala Gln Leu Val Asp Gln Pro Ile Glu Ala

2389 TCG CTA ACT CCG CAA GAT GTG GAC GAG AAA AGC ACA ATG AAT CCT CAG GAT

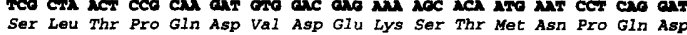

2440 GCT ATC GAC AAT AGA ACA GAG GIT CCC CCG GTA CCA GAT CCT CCC CAA GCA

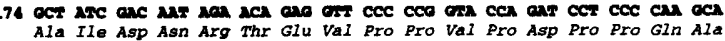
2491 TTA AGC GGG ATA GAT CGT GCG GTG AAT TCG CCG ATG AAG AAT GTG ACC GAG Leu Ser Gly Ile Asp Arg Ala Val Asn Ser Pro Met Lys Asn Val thr Glu

2542 GGC GAT GCC CAG GCG ATT CCC ATC TCC AGC AGT GCG TCC ACC CAT AAA ACG

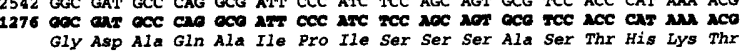
2593 CCG CAT TGAATCTOTC AAACGCTCTC GTCAGCGAGA CCGACATTCA GACAGTTCCG

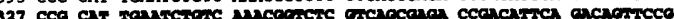
Pro His

2649 AACTCCAGCA ATGGCTAGOA CTGCGCCGGC CCCTCAGTAC CTCTGTGTTT AATTGAGCAA 7709 aAGTGACTC TGGGAACTEC GATATTACCT CAAGCTCCTT CTTCGACCGA CATCTGGGAT 2709 GAGTGAACTC TGGGACTOC GATATAACCT CAAGCTCCTT CTTCGACCGA CATCTGGGAT 2769 AGCTTTTCAA TECTGTCCTC CAAGGCAGAA TCGACGTTCT GCCCCACTGG TGCTTTCCGG

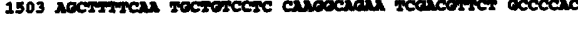
2819 ATAGCCCCTT TGGTTTCCAG ACCAGGTTG TCGAGCTCG CGAGCTGCTT CCTGGTTCCC

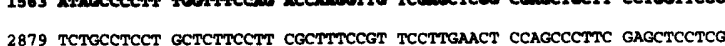
2879 TCTGCCTCCT GCTCTTCCTT CGCTTTCCGT TCCTTGAACT CCAGCCCTTC GAGCTCCTCG 2939 TCAATCTCAG TCTCATCAAT CTGTGGCCCA GCTTCACCCA TGATGTTTCC GATCTCGTCC

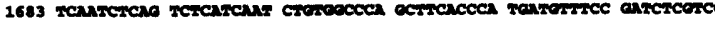
2999 ACTTTGGACA TTHCCTCGCG CAGCTCATAG ACGACATCCT CAACCTTGGA GACATCGCCG

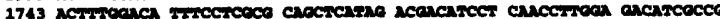
3059 AGTTGAGCAT TGAGACCTCG AAGGGCGCCC GTGCTGGATT CCATCACTTT GAGGTACTCG 3119 ACATGGTCCG TEGCCTGTTC GATCTTGAGC TGGGTTTGCT CAAGCTGTGC GAGAGTATCA

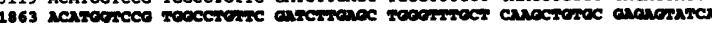
3179 AGTCTCTGCT GTAGATTATG CTCGGCGAGC TTCTTCGACC GCAATGCAGC GAGGGCTGAT 19. 3239 ACGCGGTTCT TATCACCAAG ACCGSGCTCTIT

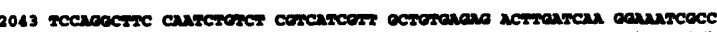

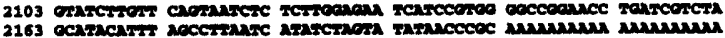

Fig. 2. Nucleotide sequence of the genomic DNA containing the nuvA gene (numbered 1-2336) compared to its CDNA sequence (bold type; numbered 1-2222) with the deduced amino acid sequence for the coding region. The limits of the sequence covered by the RT-PCR product are indicated $\downarrow$ whilst the $5^{\prime}$ start of the truncated CDNA clone pLW100 is indicated by $\Downarrow$. The genomic sequence from 1 to 2337 was obtained from clone pEA14; the $3^{\prime}$ limit of this sequence is identified by double underlining. The genomic sequence from 2134 to 3269 was obtained from cosmid pW17F02 by PCR using primers CD3 and CD8. The limits of this sequence are denoted by dashed underlining. A CAAT-like box and two TATA-like boxes are italicized and underlined. The two introns are identified as gaps in the CDNA sequence. 
in the $A$. nidulans genome and therefore the presumed overlap between them was justified. Also, the presence of multiple 'nuv $A$-like' sequences in the $A$. nidulans genome is unlikely, since Southern blots of $A$. nidulans chromosomal DNA probed with the pEA14 $2.3 \mathrm{~kb}$ EcoRI fragment did not reveal any unexpected bands (data not shown).

\section{Cloning the nuvA CDNA}

Computer homology searches with the predicted amino acid sequences of the nuv $A 11$ rescuing clone, pEA14, revealed significant homologies to the $N$. crassa uvs-2 (Tomita et al., 1993) and the S. cerevisiae R AD18 (Jones et al., 1988) gene products. The most striking homology between all three amino acid sequences occurred in a region that contained a $\mathrm{C} 3 \mathrm{HC} 4$ type of zinc finger motif. Whilst a suitable candidate for the nuv $A$ ORF had yet to be confirmed, a decision was taken to use this region of the pEA14 clone to probe an $A$. nidulans $24 \mathrm{~h}$ developmental cDNA library based on $\lambda Z A P$ (Aramayo \& Timberlake, 1990). The probe was prepared by PCR amplification of the $333 \mathrm{bp}$ fragment of pEA14 containing the zinc finger coding region using the PCR primers (Fig. 1) $\mathrm{LI} 5$ and LII $3\left(30\right.$ cycles of $94^{\circ} \mathrm{C}$ for $30 \mathrm{~s}, 55^{\circ} \mathrm{C}$ for $30 \mathrm{~s}$, $72{ }^{\circ} \mathrm{C}$ for $60 \mathrm{~s}$, finishing with $72{ }^{\circ} \mathrm{C}$ for $10 \mathrm{~min}$ ). The probe was used in a plaque hybridization. Only two independent, putative, hybridization-positive clones were identified from over 50000 plaques screened. In retrospect this result was not too surprising since recent attempts to estimate transcript size, and study the levels of expression, of nuv $A$ using Northern blots probed with the same 'zinc finger' fragment repeatedly failed to detect any message when used to probe mRNA samples from either $24 \mathrm{~h}$ cultures, similar to those used to create the cDNA library, or from cultures exposed to the DNA damaging agents MNNG or 4 NQO. All of the blots consistently produced the expected results when reprobed with the control gene, a fragment of the $A$. nidulans $\gamma$-actin gene (Fidel et al., 1988) (data not shown), and we conclude that the nuv $A$ gene is expressed at very low levels in vegetative tissue.

Since restriction enzyme analysis and partial DNA sequencing demonstrated that the two cDNA clones were identical, DNA sequencing proceeded using only one of them, pLW100. This revealed that the clone had been truncated at the $5^{\prime}$ end of the gene (Fig. 2), resulting in the loss of part of the $5^{\prime}$ coding and untranslated regions. To overcome this problem a modified version of the 'RACE no more' RT PCR method was adopted (Weis, 1994), as described in Methods. The products of the RT-PCR were detected as two faint bands of approximately $1.5 \mathrm{~kb}$ and $900 \mathrm{bp}$ on a $0.6 \%$ low melting point agarose (Bio-Rad) gel (data not shown). The bands were recovered and subjected to further PCR analysis. It was assumed that the nuv $A$-specific primer, $\mathrm{CD} 4$, had somehow become attached to the $5^{\prime}$ end of the RT-PCR product, as proposed by Weis (1994), thereby enabling the amplification to occur with just a single primer, creating a product with CD4 sites at both ends. For the PCR analysis of the RTPCR products, specific primer pairs were chosen to test this prediction and confirm that they were were derived from nuv $A$ transcripts (Fig. 1). Pair A comprised CD2, derived from the known cDNA sequence, and the genomic-sequence-derived primer LI13 which should amplify the zinc finger coding region to give a $416 \mathrm{bp}$ product; primer pair B comprised CD1, whose sequence was complementary to the CD2 primer, and the RT-PCR primer CD4. According to the known cDNA sequence, the predicted product of primer pair B would be $362 \mathrm{bp}$ and comprise one end of the RT-PCR product; the equivalent genomic sequence would be larger due to the presence of introns. Primer pair $C, C D 2$ and $C D 4$, was therefore used for PCR of the opposite end of the RTPCR fragments. This pair was predicted to give an approximately $540 \mathrm{bp}$ product from the smaller of the two RT-PCR fragments and approximately $1140 \mathrm{bp}$ from the larger fragment. PCR products were only obtained from the smaller RT-PCR fragment, but they were all of the expected sizes implying that they were derived from the nuv $A$ transcript and that CD4 primers were located at both ends of the RT-PCR product. The $362 \mathrm{bp}$ product of primer pair $B$ was sequenced directly using CD1 and CD4 as sequencing primers. The sequence obtained corresponded to that already determined for the cDNA clone pLW100. A similar sequencing strategy for the CD2/CD4 PCR product was more problematical, and it was therefore cloned into the PCR cloning vector PGEM-T (Promega) and sequenced using the M13 $(-20)$ and M13 reverse sequencing primers. The sequence derived was as expected based on the genomic sequence for that region of the nuv $A$ gene encoding the putative $\mathrm{C} 3 \mathrm{HC} 4$ type zinc finger motif.

\section{Fine mapping of nuvA}

The assignment, by mitotic mapping experiments (Osman et al., 1991), of nuv A11 to linkage group IV could not be confirmed by conventional meiotic mapping. However, the positive hybridization of the $2.3 \mathrm{~kb}$ pEA14 $A$. nidulans genomic DNA insert (Fig. 1) to pW17F02, a chromosome-IV-specific clone from the pWE15 $A$. nidulans genomic library (Brody et al., 1991) identified its site. No linkage was detected to any of the chromosome IV markers present on the meiotic mapping strain A517. Since a physical map of linkage group IV had been constructed (Wang et al., 1994), it was possible to assign the nuv $A$ gene to an approximate physical map position based on the known chromosomal location of cosmid $\mathrm{pW} 17 \mathrm{~F} 02$. Using this information, nuv $A$ was predicted to be close to bimD on the left arm of chromosome IV, since bimD also hybridized to this cosmid (R. Prade, University of Georgia, personal communication). A series of PCR experiments was then performed in an attempt to orientate nuv $A$ with respect to bimD (Fig. 1). PCR primers directed against the published sequence for bimD (accession number L03200) were used in conjunction with available nuv $A$ primers with PCR buffer 1 in the Expand Long Template PCR System (Boehringer) according to the manufacturer's recommendations (denature for $2 \mathrm{~min}$ at $94^{\circ} \mathrm{C}$, followed by 10 cycles of $94^{\circ} \mathrm{C}$ for $10 \mathrm{~s}, 62^{\circ} \mathrm{C}$ for $30 \mathrm{~s}$ and $68^{\circ} \mathrm{C}$ for $8 \mathrm{~min}$, then 20 cycles of $94^{\circ} \mathrm{C}$ for $10 \mathrm{~s}$, $62{ }^{\circ} \mathrm{C}$ for $30 \mathrm{~s}$ and $68^{\circ} \mathrm{C}$ for $8 \mathrm{~min}$, increasing by $20 \mathrm{~s}$ each 
cycle, followed by $68^{\circ} \mathrm{C}$ for $7 \mathrm{~min}$ and kept at $4{ }^{\circ} \mathrm{C}$ overnight). From these experiments we were able to determine that both genes have the same direction of transcription and that the $3^{\prime}$ end of the $\operatorname{bim} D$ gene lies approximately $2 \mathrm{~kb}$ upstream of the start of the nuv $A$ gene. This orientation was consistent with the expected locations of BamHI and $S_{s t} \mathrm{I}$ restriction enzyme sites in this region, predicted from the DNA sequence of $\operatorname{bim} D$ and a previously constructed restriction enzyme map of the equivalent region in pNUV11A40, the original nuv $A 11$ rescuing cosmid (Fig. 1).

The genetic map for chromosome IV contains very few markers in the vicinity of bimD (Clutterbuck, 1994; Käfer \& Chae, 1994), resulting in difficulty in meiotic mapping. The only other marker, the $u v s H$ gene, is $3 \mathrm{cM}$ from bimD (Käfer \& Chae, 1994). This is not inconsistent with the physical distance between nuv $A$ and $\operatorname{bim} D$, which together with the broad similarity of the nuv $A$ and $u v s H$ mutant phenotypes (sensitivity to UV and increased mitotic recombination) suggests that they could be the same gene. There are, however, significant differences in the meiotic phenotypes of nuv $A$ and $u v s H$ mutant alleles, for while $n w v A$ homozygous crosses show an absence of meiotic recombination, yet are otherwise phenotypically normal, no effect on meiotic recombination is observed for $w v s H$ homozygous crosses. This is so even in the very poorly fertile crosses involving the extreme allele uvsH77 (Käfer \& Mayor, 1986). However, the low fertility could be due to aberrant meiotic recombination. Early in our study, diploid complementation assays were performed to test nuv mutations against known uvs mutations. In those tests, nuv $A 11$ and $w v s H$ alleles complemented (Osman et al., 1991) and we concluded that they were therefore nonallelic, since there were also differences in their mutant phenotypes. Because of our recent physical mapping data however, we cannot exclude the possibility that this represents intragenic complementation, perhaps at a complex locus.

\section{The nuvA nucleotide and predicted amino acid sequences}

The nucleotide sequences of both strands of the genomic clone pEA14, the cDNA clone pLW100, the RT-PCR clone $\mathrm{pLW} 101$ and RT-PCR fragment from primer pair B have been determined (Fig. 2) and the contiguity of these fragments in the $A$. nidulans genome has been confirmed (Fig. 1). In addition, the sequence of the genomic DNA defined by primers $\mathrm{CD} 3$ and $\mathrm{CD} 8$ has been determined by PCR amplification from $\mathrm{pW} 17 \mathrm{~F} 02$. In the genomic DNA sequence preceding the ATG codon of the nuv $A$ ORF at position 1151, there are two TATA-like boxes at positions $334-340$ and $588-592$, and at position $431-433$ there is a CAAT-like box. These sites are a long way from the coding region and their functional validity has yet to be verified. A comparison of the genomic DNA sequence with the cDNA sequence has revealed the presence of two introns, one of $51 \mathrm{bp}$ and one of $60 \mathrm{bp}$. The consensus $5^{\prime}$ and $3^{\prime}$ splice junction sequences $\left(5^{\prime}-\mathrm{GT}\right.$ and $\left.3^{\prime}-\mathrm{AG}\right)$ are conserved in intron $1(1620-1634)$ but not in intron 2
(1827-1886). The genomic DNA sequence is complete for the coding region of the gene, and terminates $209 \mathrm{bp}$ before the end of the cDNA sequence. Due to difficulties in sequencing the beginning of the RT-PCR product, even after cloning, only $4 \mathrm{bp}$ of the cDNA sequence that is presumed to represent $5^{\prime}$ untranslated sequence is available. The nuv $A$ ORF comprises 1329 bp of the total $2 \cdot 2 \mathrm{~kb}$ of cDNA sequence, whilst the remaining $900 \mathrm{bp}$ is assumed to be $3^{\prime}$ untranslated sequence. The large extent of $3^{\prime}$ untranslated sequence and the observation that it contains other potential ORFs is perhaps an indication that the nuv $A$ message can undergo alternative splicing reactions and if $u v s H$ and $n w v A$ prove to be allelic, perhaps accounts for the intragenic complementation. Future studies of nuv $A$ expression will test this hypothesis. The nuv $A$ ORF encodes a 443 amino acid protein, molecular mass $48.9 \mathrm{kDa}$, containing two zinc finger motifs near the $\mathrm{N}$ terminus. The first of the zinc finger motifs is termed a $\mathrm{C} 3 \mathrm{HC} 4$ or ring finger motif and has been found in a variety of proteins involved in recombination and differentiation including the human $\mathrm{V}(\mathrm{D}) \mathrm{J}$ recombination activating protein, RAG-1 (Shatz et al., 1989), the UVS-2 protein of N. crassa (Tomita et al., 1993) and the RAD18 protein of $S$. cerevisiae (Jones et al., 1988). The second motif has the consensus sequence $\mathrm{C} / \mathrm{H}-\mathrm{X}_{2-4}-\mathrm{C} / \mathrm{H}-\mathrm{X}_{2-15^{-}}$ $\mathrm{C} / \mathrm{H}-\mathrm{X}_{2-4}-\mathrm{C} / \mathrm{H}$ (Berg, 1990).

\section{Comparisons with UVS-2 and RAD18}

Database searches with the putative nuv $A$ translation product identified significant homologies between NUVA and the translation products of the $u v s-2$ gene of $N$. crassa (Tomita et al., 1993) and the RAD18 gene of $S$. cerevisiae (Jones et al., 1988). More specifically, using the Genetics Computer Group Program GAP program (1994), 39\% of the residues were found to be identical and $57 \%$ similar to those of the UVS- 2 protein, with $25 \%$ identical and $46 \%$ similar to the RAD18 protein (Fig. 3). In a comparison between UVS- 2 and RAD18, $25 \%$ of the residues were identical and $68 \%$ homologous (Tomita et al., 1993). The highest homology exists around the two zinc finger motifs; there is $100 \%$ conservation of nine amino acid residues from the histidine of the $\mathrm{C} 3 \mathrm{HC} 4$ zinc finger. A second interesting feature is the high level of conservation in the region covered by the NUVA residues $272-280$ inclusive; these residues end the tract of significant homology between the three proteins. The putative nucleotide binding site of RAD18, the core sequence of which shares no apparent homology with either NUVA or UVS-2, is located in the C-terminal region of least homology. This may represent an important difference between the three proteins or may imply that the similarity of the RAD18 sequence to a nucleotide binding site is purely coincidental.

The phenotypes that result from mutations in these three genes are very similar. All cause an extreme sensitivity to UV light and other DNA damaging agents and show increased levels of $\mathrm{UV}$-induced mutation (nuv $A$, unpublished results; uvs-2, Tomita et al., 1993; RAD18, Cassier-Chauvat \& Fabre, 1991), which in the case of 


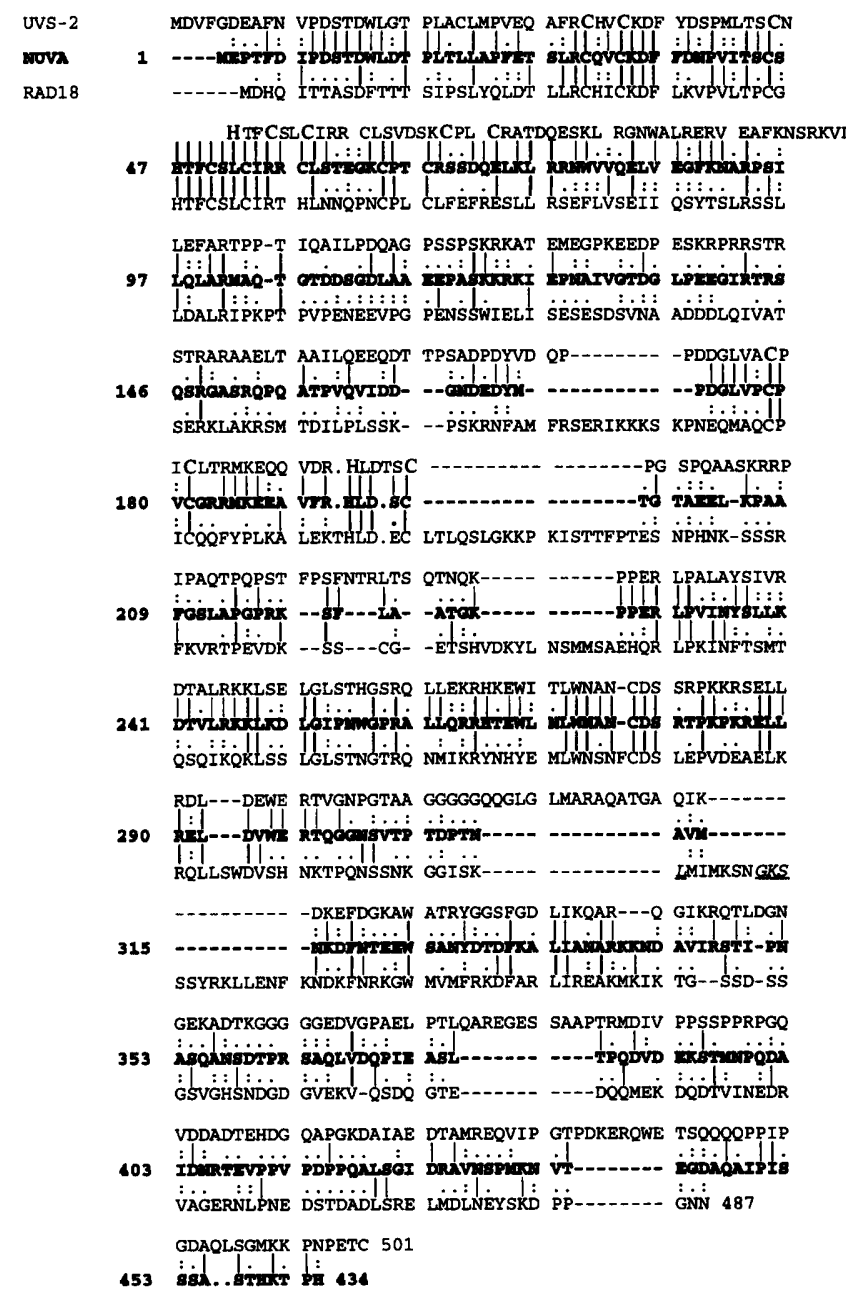

Fig. 3. Comparison of the deduced amino acid sequence of $A$. nidulans NUVA to those of the $N$. crassa UVS-2 and S. cerevisiae RAD18. Identical residues are connected by a line, conserved residues are connected by a bold line. Evolutionarily related amino acids (as defined by Gribskov \& Burgess, 1986) are indicated with dots. The conserved zinc-binding cysteine and histidine residues, present in the two zinc finger motifs, are highlighted in the UVS-2 sequence. The putative core sequence for the nucleotide binding site of RAD18 is underlined.

RAD18 is thought to be due to the stimulation of the error-prone repair pathway. $\mathrm{R} A D 18$ mutants, like those of nuv $A$, show an increase in mitotic recombination frequencies. They also show an increase in the frequency of UV- or other DNA damaging-agent-induced mitotic recombination, an effect which has been attributed to the channelling of recombinogenic structures into the RAD52 recombination repair pathway. Due to results from an excision repair assay in $N$. crassa (Worthy \& Epler, 1973), $u v s-2$ was originally thought to be required for excision repair of DNA damage. However, more recent experiments have shown that it is not required for the excision of thymine dimers (Ishii et al., 1991) and is therefore unlikely to be involved in excision repair of these lesions. RAD18 is a member of the RAD6 epistasis group and is presumed to act, in consort with RAD5 and complexed with RAD6, in an error-free post-replication repair pathway, whereas REV1 and REV3, other members of the RAD6 epistasis group, are thought to be required for the mutagenic post-replication pathway (Prakash et al., 1993). One suggestion is that the ssDNA binding property of RAD18 is used to target RAD6 to areas of DNA damage where the separate ubiquitin-conjugating function of RAD6 could be used to modify the stalled replication machinery (Bailly et al., 1994). Unlike nuv A11, none of the mutants of either uvs-2 or RAD18 have been shown to have any effects on either meiosis or meiotic recombination, although RAD18 transcript levels are increased during meiosis (Jones \& Prakash, 1991) and rad1 $\mathrm{rad} 18$, rad $2 \mathrm{rad} 18$ and $\mathrm{rad} 3 \mathrm{rad} 18$ double mutants suffer from a drastic reduction in spore viability. From these observations and the similarity to NUVA, it seems likely that RAD18 will, using different experimental conditions, be found to be involved in meiotic recombination since the effects seen in the nuv $A 11$ mutant are most dramatic when the markers are very close, as in the intragenic recombination assay.

Further work is required to establish how mutations in nuv $A$ might have opposing effects on recombination during meiosis and mitosis and how these are related to its effects on DNA repair. Given their juxtapositions on chromosome IV and the similar responses to DNA damaging agents, it will be interesting to find out the relationship, if any, between $w v s H, \operatorname{bim} D$ and $n u v A$.

\section{ACKNOWLEDGEMENTS}

This work was supported by grants from the Wellcome Trust to Peter Strike and Brian Tomsett. The authors acknowledge the contribution of Angela Bardon who synthesized a number of the PCR primers and used the automatic DNA sequencer to verify some of the genomic and cDNA sequences. This work benefited from the SEQNET facility.

\section{NOTE ADDED IN PROOF}

The recent publication of the Aspergillus uvs $H$ gene sequence (Yoon et al., 1995, Mol Gen Genet 248, 174-181) confirms that nuv $A$ and $w v s H$ are the same gene.

\section{REFERENCES}

Aramayo, R. \& Timberlake, W. F. (1990). Sequence and molecular structure of the Aspergillus nidulans y $A$ (laccase-I) gene. Nucleic Acids Res 18, 3415.

Bailly, V., Lamb, J., Sung, P., Prakash, S. \& Prakash, L. (1994). Specific complex formation between RAD6 and RAD18 proteins: a potential mechanism for targeting RAD6 ubiquitin-conjugating activity to DNA damage sites. Genes $\&$ Dev 8, 811-820.

Bainbridge, B. W. (1971). Macromolecular composition and nuclear division during spore germination in Aspergillus nidulans. J Gen Microbiol 66, 319-325.

Ballance, D. J. \& Turner, G. (1985). Development of a high frequency of transforming vector for Aspergillus nidulans. Gene 33, 321-327.

Berg, J. M. (1990). Zinc fingers and other metal-binding domains. $J$ Biol Chem 265, 6513-6516. 
Bergan, G. G. \& Morris, N. R. (1983). Kinetics of the nuclear division cycle of Aspergillus nidulans. J Bacteriol 156, 155-160.

Brody, H., Griffith, J., Cuticchia, A. J., Arnold, J. \& Timberlake, w. (1991). Chromosome-specific recombinant DNA libraries from the fungus Aspergillus nidulans. Nucleic Acids Res 19, 3105-3109.

Bullock, W. O., Fernandez, J. M. \& Short, J. M. (1987). XL1-blue: a high efficiency plasmid transforming $\operatorname{rec} A$ Escherichia coli strain with beta-galactosidase selection. Bio/Techniques 5, 376.

Cassier-Chauvat, C. \& Fabre, F. (1991). A similar defect in UVinduced mutagenesis conferred by the rad6 and rad18 mutations of Saccharomyces cerevisiae. Mutat Res 254, 247-253.

Clutterbuck, A. J. (1994). Linkage map and loci. In Aspergillus: 50 Years On. Prog Ind Microbiol 29, 791-827.

Cove, D. J. (1966). The induction and repression of nitrate reductase in the fungus Aspergillus nidulans. Biocbim Biopbys Acta 113, 51-56.

Feinberg, A. P. \& Vogelstein, B. (1983). A technique for radiolabelling DNA restriction endonuclease fragments to high specific activity. Anal Biochem 132, 6-13.

Fidel, S., Doonan, J. H. \& Morris, N. R. (1988). Aspergillus nidulans contains a single actin gene which has unique intron locations and encodes a $\gamma$-actin gene. Gene 70, 283-293.

Game, J. C. (1983). Radiation sensitive mutants and DNA repair in yeast. In Yeast Genetics: Fundamental and Applied Aspects, pp. 109-137. Edited by J. F. T. Spencer, D. M. Spencer \& A. R. W. Smith. New York: Springer-Verlag.

Genetics Computer Group (1994). Program Manual for the Wisconsin Package, Version 8. Madison, Wisconsin, USA: GCG

Gribskov, M. \& Burgess, R. R. (1986). Sigma factors from Escherichia coli, B. subtilis, phage SP-01 and phage T4 are homologous proteins. Nucleic Acids Res 14, 6745-6763.

Hanahan, D. (1983). Studies on transformation of Escherichia coli with plasmids. $J$ Mol Biol 166, 557-580.

Haynes, R. H. \& Kunz, B. I. (1981). Repair and mutagenesis in yeast. In The Molecular Biology of the Yeast Saccharomyces. Life Cycle and Inheritance, pp. 371-414. Edited by J. N. Strathern, E. W. Jones \& J. R. Broach. Cold Spring Harbor, NY: Cold Spring Harbor Laboratory.

Ishii, C., Nakamura, K. \& Inoue, H. (1991). A novel phenotype of an excision-repair mutant in Neurospora crassa: mutagen sensitivity of mus-18 mutant is specific to UV. Mol \& Gen Genet 228, 33-39.

Jones, J. S. \& Prakash, L. (1990). Transcript levels of Saccharomyces cerevisiae DNA repair gene $R A D 18$ increase in UV irradiated cells and during meiosis but not during the mitotic cell cycle. Nucleic Acids Res 19, 893-898.

Jones, J. S., Weber, S. \& Prakash, L. (1988). The Saccharomyces cerevisiae $\mathrm{R} A D 18$ gene encodes a protein that contains potential zinc finger domains for nucleic acid binding and a putative nucleotide binding sequence. Nucleic Acids Res 16, 7119-7131.
Kafer, E. \& Chae, S. (1994). Phenotypic and epistatic grouping of hypo- and hyper-rec mus mutants in Aspergillus. Curr Genet 25, 223-232.

Käfer, E. \& Mayor, O. (1986). Genetic analysis of DNA repair in Aspergillus: evidence for different types of MMS-sensitive hyperrec mutants. Mutat Res 161, 119-134.

Osman, F., Cotton, C., Tomsett, B. \& Strike, P. (1991). Isolation and characterisation of nuv11, a mutation affecting meiotic and mitotic recombination in Aspergillus nidulans. Biocbimie 73, 321-327.

Pontecorvo, G., Roper, J. A., Hemmons, L. M., MacDonald, K. D. \& Bufton, A. W. J. (1953). The genetics of Aspergillus nidulans. $A d v$ Genet 5, 141-238.

Prakash, S., Sung, P. \& Prakash, L. (1993). DNA repair genes and proteins of Saccharomyces cerevisiae. Annu Rev Genet 27, 33-70.

Raeder, U. \& Broda, P. (1985). Rapid preparation of DNA from filamentous fungi. Letts Appl Microbiol 1, 17-20.

Roman, H. \& Ruzinski, M. M. (1990). Mechanisms of gene conversion in Saccharomyces cerevisiae. Genetics 124, 7-25.

Sambrook, J., Fritsch, E. F. \& Maniatis, T. (1989). Molecular Cloning: A Laboratory Manual, Second Edition. Cold Spring Harbor, NY: Cold Spring Harbor Laboratory.

Sanger, F., Nicklen, S. \& Coulson, A. R. (1977). DNA sequencing with chain terminating inhibitors. Proc Natl Acad Sci USA 74, 5463-5467.

Shatz, D. G., Oettinger, M. A. \& Baltimore, D. (1989). The V(D)J recombination activating gene $R A G-1$. Cell 59, 1035-1048.

Sylvers, L. A. \& Beresten, S. (1993). Loss of resolution in gel electrophoresis of RNA : a problem associated with the presence of formaldehyde gradients. BioTechniques 14, 380-381.

Tomita, H., Soshi, T. \& Inoue, H. (1993). The Neurospora uvs-2 gene encodes a protein which has homology to yeast RAD18, with unique zinc finger motifs. Mol \& Gen Genet 238, 225-233.

Tomsett, A. B. \& Cove, D. J. (1979). Deletion mapping of the niiAniaD region in Aspergillus nidulans. Genet Res 34, 19-32.

Wang, Y. H., Prade, R. A., Griffith, J., Timberlake, W. E. \& Arnold, J. (1994). A fast random cost algorithm for physical mapping. Proc Natl Acad Sci USA 91, 11094-11098.

Waring, R. B., May, G. S. \& Morris, N. R. (1989). Characterization of an inducible expression system in Aspergillus nidulans using alc $A$ and tubulin-coding genes. Gene 79, 119-130.

Weis, J. H. (1994). 'RACE no more'; an alternative approach to cloning the $5^{\prime}$ end of transcripts. Nucleic Acids Res 22, 3427-3428.

Worthy, T. E. \& Epler, J. L. (1973). Biochemical basis of radiation sensitivity in mutants of Neurospora crassa. Mutat Res 19, 167-173.

Received 23 April 1995; revised 22 September 1995; accepted 28 September 1995. 